Article

\title{
Temperature Fluctuation Attenuation of Circulating Cooling Water Using Dynamic Thermal Filtering
}

\author{
Yesheng Lu${ }^{\oplus}$, Junning Cui *, Jiubin Tan, Xingyuan Bian and Yamin Zhao \\ Center of Ultra-precision Optoelectronic Instrument, Harbin Institute of Technology, Harbin 150080, China; \\ luyesheng@163.com (Y.L.); jbtan@hit.edu.cn (J.T.); bianxingyuan@hit.edu.cn (X.B.); zhaoyamin@163.com (Y.Z.) \\ * Correspondence: cuijunning@hit.edu.cn; Tel.: +86-451-8640-2258
}

Received: 17 June 2020; Accepted: 30 July 2020; Published: 2 August 2020

\begin{abstract}
The Demand for circulating cooling water (CCW) with high temperature stability and a quick response to temperature control is essential for precision engineering, so a dynamic thermal filtering method is proposed in this paper. Some CCW is bypassed, blocked, and used as a thermal capacity medium, and the temperature fluctuation of $\mathrm{CCW}$ is significantly reduced by heat exchanging with the medium. The temperature of the medium dynamically follows the set value of the CCW temperature by real time updating, and so realizes a quick CCW temperature control response. The attenuation ratio of temperature fluctuation was derived, theoretically validating the effectiveness of the method. The experimental results indicate that a CCW temperature fluctuation attenuation ratio of tens of $\mathrm{dB}(-3.47 \mathrm{~dB},-6.91 \mathrm{~dB},-10.97 \mathrm{~dB}$ and $-15.28 \mathrm{~dB}$ corresponding to temperature fluctuation frequencies of $0.01 \mathrm{~Hz}, 0.025 \mathrm{~Hz}, 0.053 \mathrm{~Hz}$ and $0.105 \mathrm{~Hz}$, respectively) is achieved by the proposed method. The updating time of thermal capacity medium is $82 \mathrm{~s}$, which means that the temperature fluctuation attenuation remains functionally valid when the set value of CCW changes. The proposed method is low cost in operation and provides an effective approach to satisfy the challenging demand for CCW with high stability and a good dynamic temperature control performance.
\end{abstract}

Keywords: dynamic thermal filtering; circulating cooling water; temperature stability; quick response; lithography

\section{Introduction}

In the fields of precision manufacturing, more than $40-70 \%$ of machining errors result from thermal deformation of machine tools and work pieces [1], while circulating water cooling is a key technology against thermal pollution. Circulating cooling water (CCW) is usually used for temperature maintenance of motors, drivers, and other power devices. Therefore, the requirement for CCW with high temperature stability and quick response of temperature control is found in the fields of lithography, optical machining, and so on [2-5].

Lithography, for instance, has a requirement for overlay accuracy of up to $1.4 \mathrm{~nm}$, while the technical node of the advanced stepping and scanning lithography machine is below $45 \mathrm{~nm}$. However, the peak power of the thermal pollution produced by motors, drivers, laser sources, and various electrical circuits reaches up to several kilowatts. Thus, CCW with a temperature stability of $\pm 0.01 \mathrm{~K}$ is used as a direct cooling medium to maintain the temperature stability of the objective lens within \pm 0.01 $\mathrm{K}$, and also as a temperature reference medium to produce an "air shower" for temperature stability of up to $2.3 \mathrm{mK} / 5 \mathrm{~min}$, to maintain the air refractive index for the ultra-precision laser interferometry [3,5]. Besides, it is preferred that the temperature of CCW is able to vary quickly along with the pre-set power curve of motors, rather than conventional motor cooling with CCW of constant temperature. In the applications of the electrical spindle cooling of optical machining [6-8], a CCW temperature control response time of tens of seconds of is also demanded, to achieve "servo" thermal management 
according to the variation of the spindle rotating speed. For example, in 2015, Weiguo Gao used two CCW machines to provide two streams of CCW with different temperatures, then mixed the two streams to produce the CCW for spindle thermal control. As a result, the temperature of mixed CCW can be regulated quickly by modifying the mixing percentage [6]. Therefore, precision manufacturing is marching forward to an "atom era"; accordingly, CCW temperature control with high stability and good dynamic performance becomes a challenging task to be solved.

Conventionally, in order to improve the temperature stability of CCW, thermal inertia of CCW is enlarged by introducing a water tank into the temperature control system of CCW. As a result, a quick temperature control response can hardly be achieved due to the enlarged distributive delay which comes from the introduced thermal inertia [9-13], i.e., the dynamic performance is sacrificed for higher temperature stability. Lawton K.M. et al. presented temperature fluctuation attenuators based on the principle of introducing additional thermal capacity medium. In 2001, Lawton used water, which is sealed in one chamber of a heat exchanger, as thermal capacity medium. Then, CCW flows through another chamber of the heat exchanger, thus the temperature fluctuation of CCW is reduced by the large thermal capacity of the sealed water [14]. In 2003, Lawton used stainless-steel balls as thermal capacity material, with CCW flowing through the balls, thus the temperature fluctuation of CCW is reduced by the large thermal capacity of the stainless-steel balls [15]. Materials with large thermal capacity, including stainless-steel balls and water, are introduced as the medium, and the temperature fluctuation of water is smoothed by heat exchanging with the medium. This method provides a new approach to the high attenuation ratio of water temperature fluctuation. However, the attenuators only function around a fixed temperature point. Once the set value of the CCW temperature is changed, the attenuator is functionally invalid, and becomes a thermal interference source, which means that the method is only applicable for water cooling applications that demand CCW of constant temperature. Temperature fluctuation attenuators using phase change material (PCM) as thermal capacity medium [16-20] are also proposed and attract much attention. PCM has large latent thermal capacity at its phase change temperature point, and can absorb or release great thermal energy during the process of phase change. In 2004, Esam M. Alawadhi presented a numerical study to evaluate the temperature fluctuation attenuation of water based on PCM, which indicated that lower flow rate of water and larger quantity of PCM could improve the performance of temperature fluctuation attenuation [18]. In 2014, Pavel Charvat presented the experimental investigation to validate the stabilization of the flowing water temperature with PCM, and a kind of paraffin-based PCM is used to cover a tube as thermal capacity medium. As a result, more than $90 \%$ of temperature fluctuation of the water flowing through the tube is reduced [16,17]. A variety of PCMs with different phase change temperature points have been investigated and used to form attenuators. However, a PCM has a fixed phase change temperature point. Therefore, one PCM based attenuator can only reduce the temperature fluctuation around the fixed temperature point of the employed PCM. Besides, new materials like nanofluids have are also attracting attention, since the enhanced conventional heat transfer performance can improve the temperature fluctuation attenuation [21,22].

Therefore, previous work mostly concentrates on the realization of high temperature stability of $\mathrm{CCW}$, while the dynamic performance of temperature control is rarely paid attention to. Therefore, a dynamic thermal filtering method (DTFM) is proposed in this paper. Some of the CCW is blocked and used as thermal capacity medium to filter the temperature fluctuation of CCW. The medium can be real time updated to dynamically follow the set value of CCW temperature, thus to achieve the quick response of CCW temperature control. The proposed method is theoretically and experimentally validated.

\section{Principle}

The basic concept of the proposed DTFM is shown in Figure 1. The DTFM attenuator consists of a heat exchanger, two servo valves, two precision temperature sensors, and a control module. The control module is used to implement on/off control of the servo valves according to the feedback of the 
temperature sensors. The attenuator is cascaded together with a CCW machine and a thermal load to compose an enhanced CCW temperature control system.

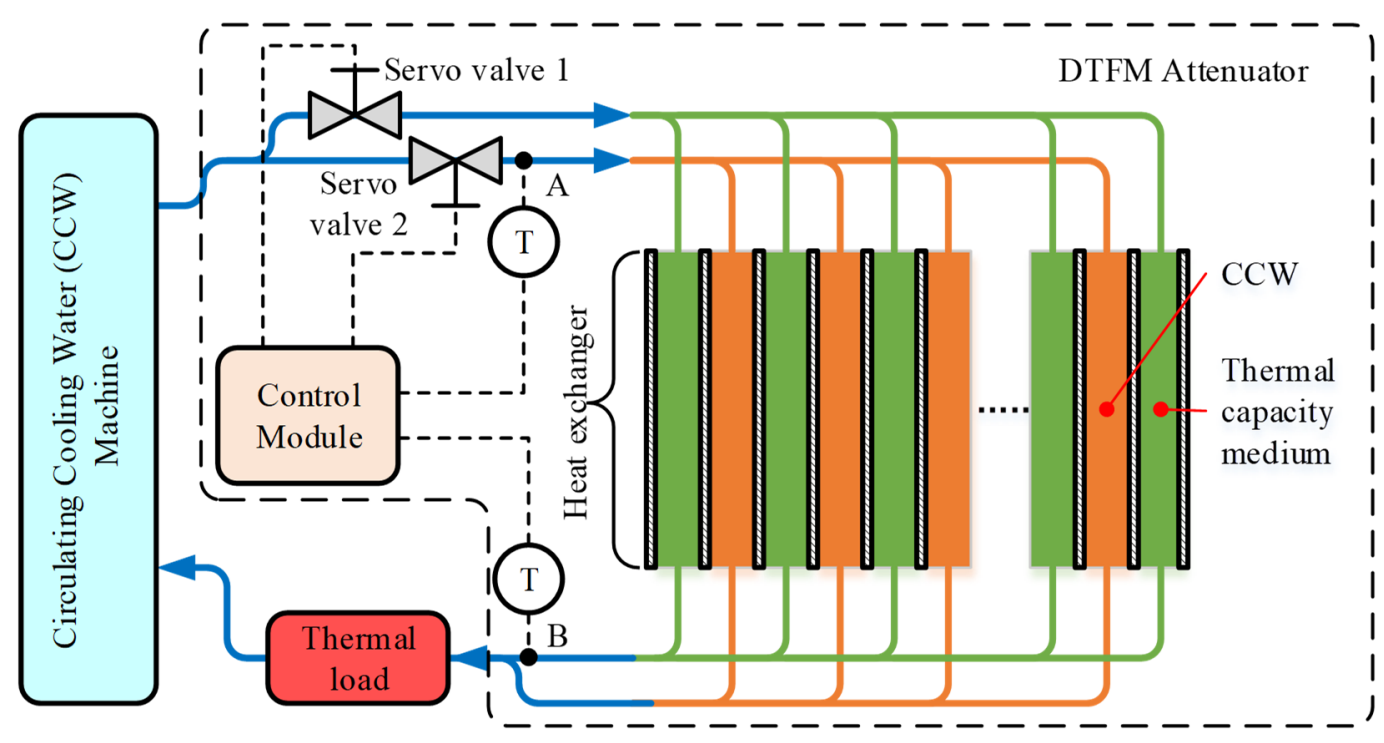

Figure 1. Schematic diagram of the enhanced circulating cooling water (CCW) system with the dynamic thermal filtering method (DTFM) attenuator.

The high temperature stability of CCW is achieved by thermal filtering. As shown in Figure 1, some CCW is bypassed and blocked in one chamber of the heat exchanger, serving as thermal capacity medium. Temperature fluctuation of $\mathrm{CCW}$, which flows through the other chamber of the heat exchanger, is attenuated by the heat exchanging with the medium. Therefore, the temperature stability of the CCW is significantly improved through thermal filtering effect.

The quick response of CCW temperature control is achieved by making the temperature of thermal capacity medium dynamically follow the set value of CCW temperature through the real time updating of the medium. When the temperature set value of the CCW machine changes, temperature sensor A detects the change, then provides feedback signal to the control module. Then the control module switches on servo valve 1 and switched off servo valve 2 to make CCW flow into the thermal capacity medium chamber to update the medium. Meanwhile, the temperature of the outflow from the medium chamber is monitored by temperature sensor $B$. When the temperature at point $B$ equals to the temperature at point $\mathrm{A}$, which means that the water in the medium chamber is totally updated, the servo valve 1 is switched off and the servo valve 2 is switched on. In this way, the change of temperature set value of CCW is dynamically followed.

The updating time of the thermal capacity medium $T_{\text {med }}$ can be given by

$$
T_{\text {med }}=\frac{V_{\text {med }}}{F_{\text {med }}}
$$

where $V_{\text {med }}$ is the volume of the thermal capacity medium chamber, and $F_{\text {med }}$ is the volume flow rate of CCW.

Before that the DTFM attenuator is introduced into the enhanced CCW system, the response time of CCW temperature control is determined by the dynamic performance of the temperature closed loop control of the CCW machine. In general, the response time of the temperature control of a CCW machine used in precision manufacturing ranges from tens of second to several minutes. After the DTFM attenuator is cascaded into the system, the response time of the temperature control of the system $T_{\text {sys }}$ can be expressed as

$$
T_{\text {sys }}=\max \left(T_{\text {mac }}, T_{\text {med }}\right)
$$


where $T_{\text {mac }}$ is the response time of temperature control of the CCW machine, and $T_{\text {med }}$ is the updating time of thermal capacity medium. Therefore, a design criterion of DTFM attenuator can be expressed as follows:

$$
T_{\text {mac }} \geq T_{\text {med }}
$$

If the criterion is satisfied, the quick response of CCW temperature control is not degraded.

\section{Modeling}

The DTFM attenuator is designed using a tube-tank heat exchanger for its high heat exchanging efficiency with compact structure. The structure of the tube-tank heat exchanger is shown in Figure 2. It consists of a square tank and an array of parallel tubes evenly arranged in the tank. The volume of the tank is divided into two chambers. One chamber is between the tubes and the wall of the tank, serving as the thermal capacity medium chamber. The other chamber is given by the inner volume of all tubes, serving as the CCW chamber. So CCW flows through the tubes, and the tubes are evenly immersed in the thermal capacity medium. A distributor is set in the upper part of the heat exchanger to guide CCW to flow into the tube array. A collector is set in the lower part of the heat exchanger to converge CCW from the tube array. The effect of temperature fluctuation attenuation is mainly contributed by the tube array, and partly contributed by the upper distributer and lower collector.
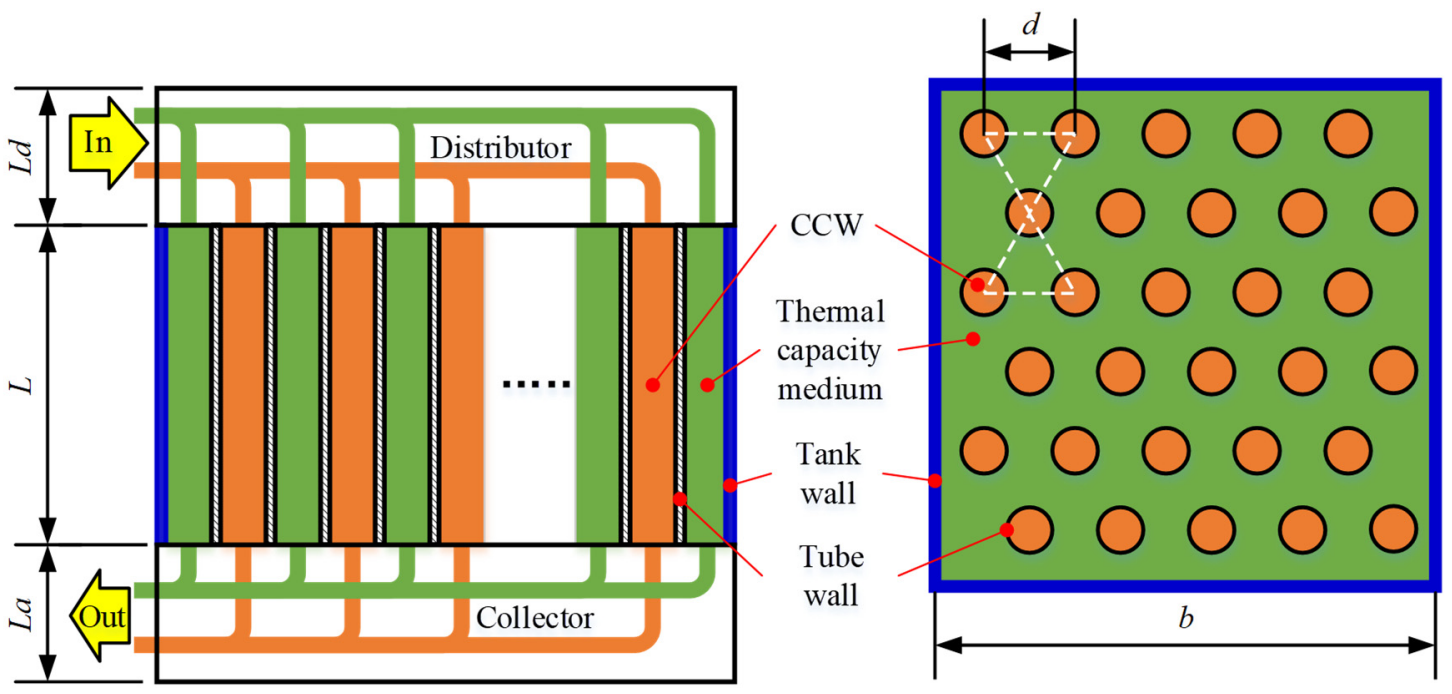

Figure 2. Axial and radial sectional views of tube-tank heat exchanger.

The designed tube-tank heat exchanger is composed of 36 tubes and a stainless-steel tank. The length of each tube $L_{\text {tube }}$ is $0.7 \mathrm{~m}$, the diameter of each tube $R_{\text {tube }}$ is $8 \mathrm{~mm}$, and the center spacing between two neighboring tubes $d$ is $32 \mathrm{~mm}$. The height of the tank $L$ is $0.7 \mathrm{~m}$, and the width $b$ is $0.23 \mathrm{~m}$. The total flow rate of CCW $F_{\mathrm{m}}$ is $16 \mathrm{~L} / \mathrm{min}$.

CCW flows into the upper distributor from the inlet header, and then flows through all tubes with same flow rate. Since the tubes are evenly immersed in the thermal capacity medium, spatial structural symmetry results in the same thermal characteristics of all tubes. The flow rate is kept small enough to make the laminar flow dominant in the tubes. Therefore, only convective heat transfer is considered to calculate the temperature fluctuation attenuation of the tube array, while the effect of mixing in the tubes is ignored. On the other hand, in the lower collector, sub-streams from the tubes act as jets and converge together, thus water mixing rather than heat transfer is the main effect contributing to CCW temperature averaging. The tank is covered with thermal isolation material to avoid heat exchange with ambient air. 
The temperature fluctuation attenuation of the DTFM attenuator is mathematically modeled by using transfer function method with reference to [14]. Transfer functions of the distributor, the tube-tank part, and the collector are defined as the fluctuation ratios of output temperature to input temperature of CCW. The total temperature fluctuation attenuation ratio of the DTFM attenuator is the product of transfer functions of all the three parts.

The transfer functions of the distributor, tube-tank part and collector are expressed as follows:

$$
\begin{gathered}
r_{\text {dis }}(f)=\exp \left(\frac{u_{\mathrm{a}}-\sqrt{u_{\mathrm{a}}^{2}+4\left(\lambda / \rho c_{\mathrm{w}}\right) 2 j \pi f C_{\mathrm{a}}}}{2 \lambda / \rho c_{\mathrm{w}}} L_{\mathrm{d}}\right) \\
r_{\text {cel }}(f)=\frac{1}{1+\left(\rho V_{\mathrm{acc}} / F_{\mathrm{m}}\right) 2 j \pi f} \\
r_{\text {att }}(f)=\exp \left(-\frac{1}{f_{\mathrm{m}} c_{\mathrm{w}} R} \operatorname{Re}\left(\frac{2 j \pi f R C_{\mathrm{a}}}{2 j \pi f R C_{\mathrm{a}}+1}\right)\right)
\end{gathered}
$$

where $\rho$ is the density of water, $V_{\text {dis }}$ is the volume of distributor, $F_{\mathrm{m}}$ is the total volume flow rate of $\mathrm{CCW}, f_{\mathrm{m}}$ is the volume flow rate of each tube, $u_{\mathrm{a}}$ is the average water velocity in the collector, $\lambda$ is thermal conductivity of water, $C_{\mathrm{a}}$ is the thermal capacity of a single tube, $L_{\mathrm{a}}$ and $L_{\mathrm{d}}$ are the height of collector and distributor respectively, $c_{\mathrm{w}}$ is the specific thermal capacity of water, and $R$ is the thermal resistance of the heat exchanger. The CCW temperature fluctuation is defined as the maxima of peak-to-peak value of temperature oscillations of CCW temperature.

The total temperature fluctuation attenuation ratio of the DTFM attenuator is

$$
r(f)=r_{\text {dis }}(f) r_{\text {cel }}(f) r_{\text {att }}(f)
$$

According to Equation (1), the updating time of the thermal capacity medium $T_{\text {med }}$ is

$$
T_{\text {med }}=\frac{\left(b^{2} L-N L \pi\left(R_{\text {tube }} / 2\right)^{2}\right) \rho}{F_{\mathrm{m}}}=82 \mathrm{~s}
$$

The response time of temperature control of the CCW machine used in this paper is $\sim 200 \mathrm{~s}$, so the design criterion of the DTFM attenuator given by Equation (3) is well satisfied, and the dynamic performance of the CCW temperature control is guaranteed. On the other hand, the band of closed loop temperature control of the CCW machine is from 0 to $0.005 \mathrm{~Hz}$, which means that the CCW temperature fluctuation below $0.005 \mathrm{~Hz}$ due to power fluctuation of the thermal load or other thermal interference can be well reduced by closed loop temperature control of the CCW machine. However, the temperature fluctuation above $0.005 \mathrm{~Hz}$ is beyond the capability of the CCW machine, which is intended to be attenuated by the DTFM attenuator.

The theoretical temperature fluctuation attenuation ratio of the DTFM attenuator is shown in Figure 3. The temperature fluctuation attenuation ratio above $0.01 \mathrm{~Hz}$ is better than $-10 \mathrm{~dB}$. In addition, the higher the frequency of CCW temperature fluctuation is, the better the attenuation ratio will be. Therefore, the temperature stability performance is effectively enhanced while the dynamic response is kept, when the DTFM attenuator is introduced into the system. The challenging demand for the precision and dynamic temperature control of $\mathrm{CCW}$ in precision manufacturing is well met. 


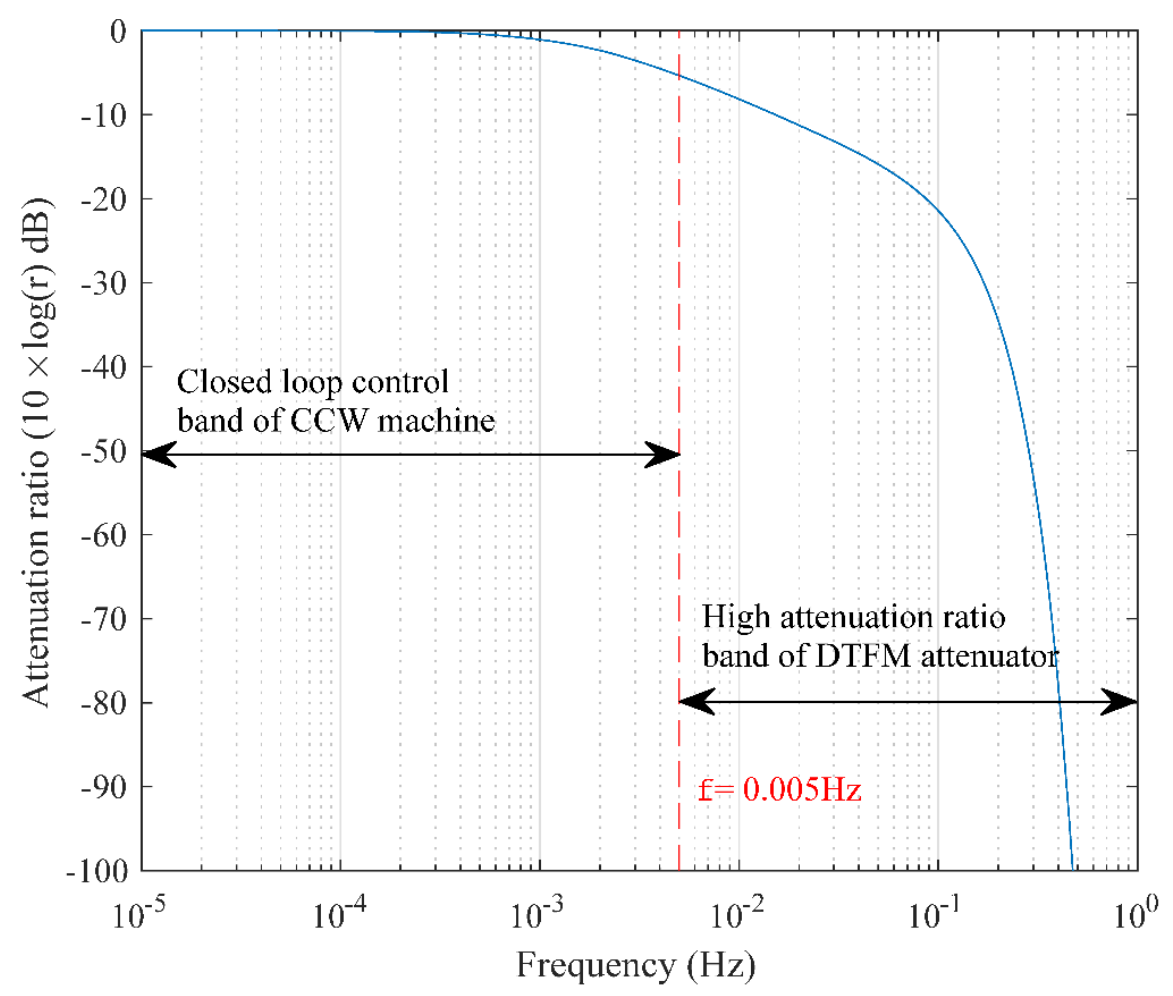

Figure 3. Theoretical temperature fluctuation attenuation ratio of the proposed DTFM attenuator.

\section{Experiment and Discussion}

\subsection{Experimental Setup}

The effectiveness of the proposed DTFM method is experimentally verified. The schematic diagram and photo of the experimental setup are shown in Figures 4 and 5 respectively.

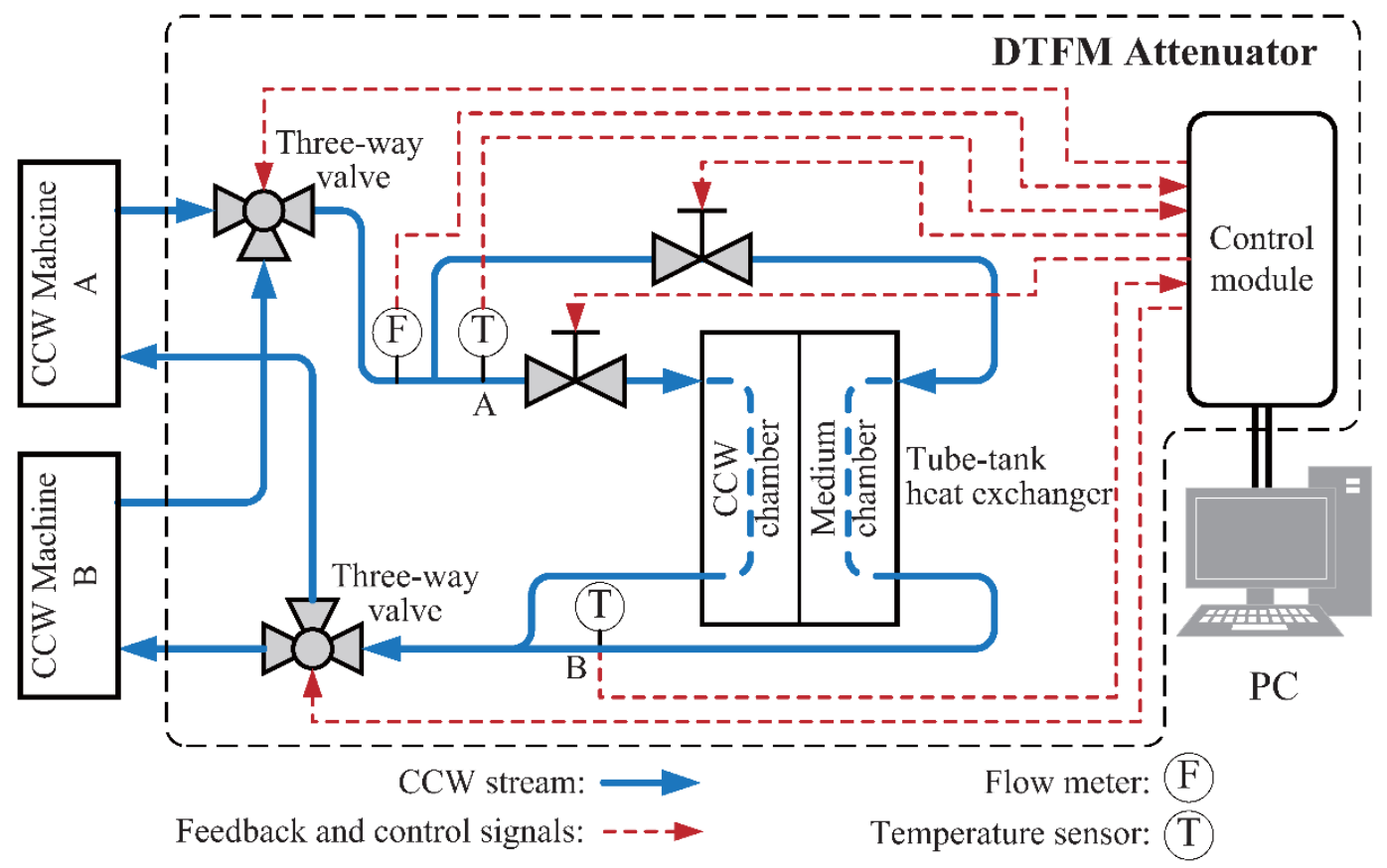

Figure 4. Schematic diagram of experimental setup. 


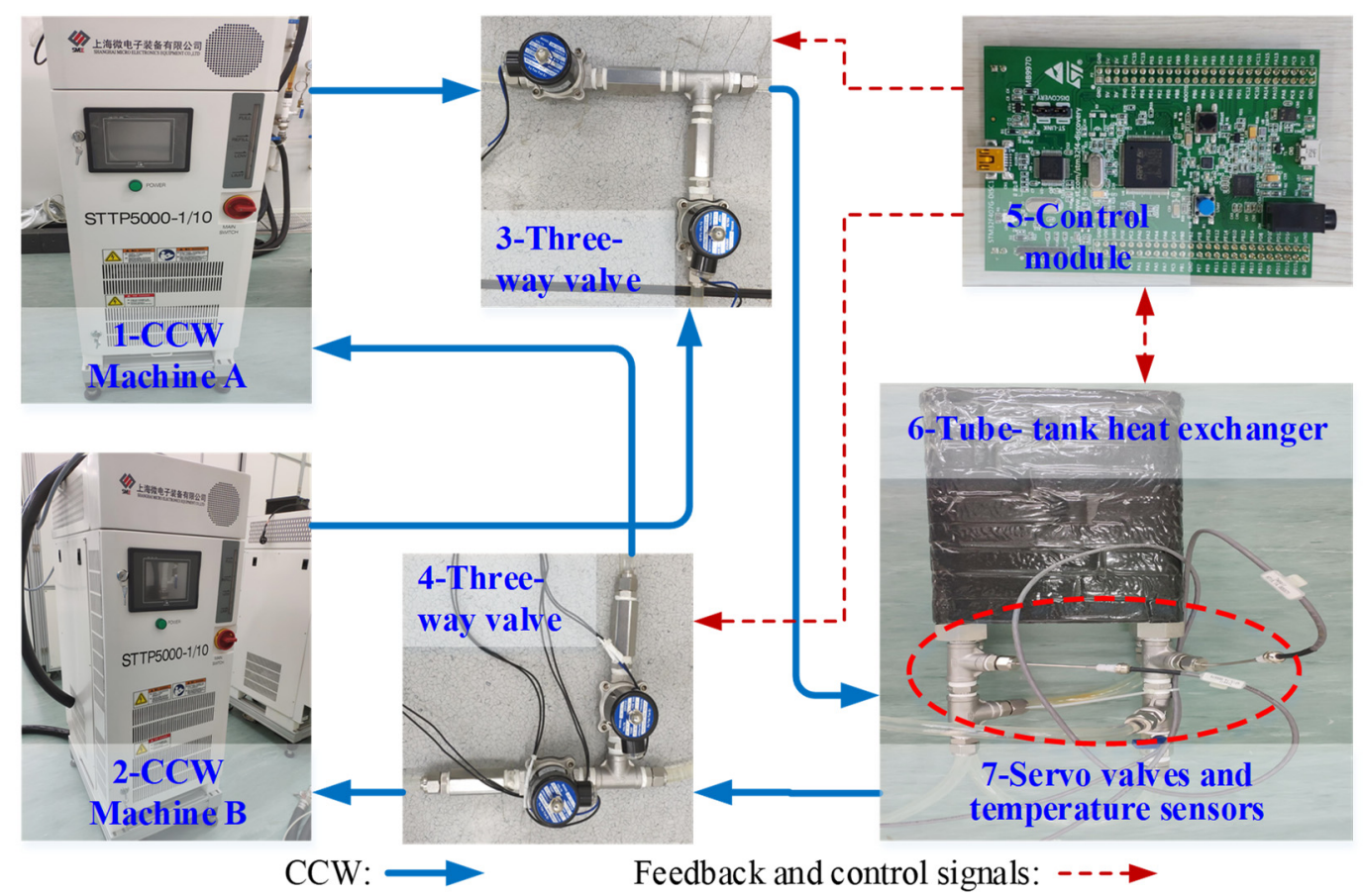

Figure 5. Photo of experimental setup (First CCW flow loop: 1-3-6-4-1; Second CCW flow loop: 2-3-6-4-2. Signal loop: 7-5-3, 4).

Two CCW machines (STTP5000-1/10 of SMEE) are used to produce the streams of CCW with different temperatures. Each CCW machine is capable of supplying CCW with a maximum flow rate of $55 \mathrm{~L} / \mathrm{min}$ and temperature stability of $\pm 0.01^{\circ} \mathrm{C}$. The two streams of CCW are alternately pumped into the DTFM attenuator through the control of a pair of electromagnetic three-way valves. In this way, a stream of CCW with square temperature waveform is produced, serving as the standard test signal for the DTFM attenuator. The amplitude of the square waveform depends on the difference in temperature of the two CCW streams from the two CCW machines, and the frequency of the square waveform depends on the switching frequency of the three-way valves.

Two temperature sensors (5641 of Fluke) with an accuracy of $\pm 0.001{ }^{\circ} \mathrm{C}$ are used to monitor the temperature at point A and B of the DTFM attenuator. A flowmeter (FD-Q10C of Keyence) with the repeatability of $\pm 0.5 \%$ in the full measuring range of $0-40 \mathrm{~L} / \mathrm{min}$ is used to measure the CCW flow rate. A control module (homemade with STM32F407 as CPU) is used for valve control and data acquisition. A PC is used as the human machine interface.

\subsection{Results and Discussion}

The temperature fluctuation attenuation ratio of the DTFM attenuator is tested. Additionally, the temperature set values of the two CCW machines are $22.5^{\circ} \mathrm{C}$ and $21.5^{\circ} \mathrm{C}$ respectively. In actual $\mathrm{CCW}$ temperature control systems, the frequency of CCW temperature fluctuation is hardly over 0.1 $\mathrm{Hz}$. Moreover, the CCW temperature fluctuation of frequency lower than $0.005 \mathrm{~Hz}$ can be directly eliminated by the temperature closed loop feedback control of the CCW temperature control system. Therefore, the switching frequencies of the two three-way valves are defined as $0.01 \mathrm{~Hz}, 0.02 \mathrm{~Hz}$, and $0.05 \mathrm{~Hz}$ for three experiment times.

It is hoped that a CCW stream with ideal square temperature waveform could be obtained. However, because of the thermal inertia between the outer header of the CCW machines and the inlet header of the DTFM attenuator, including thermal inertia of pipes, valves, and so on, the temperature waveform at inlet header of the DTFM attenuator is smoothed and distorted, as shown in Figure 6. 


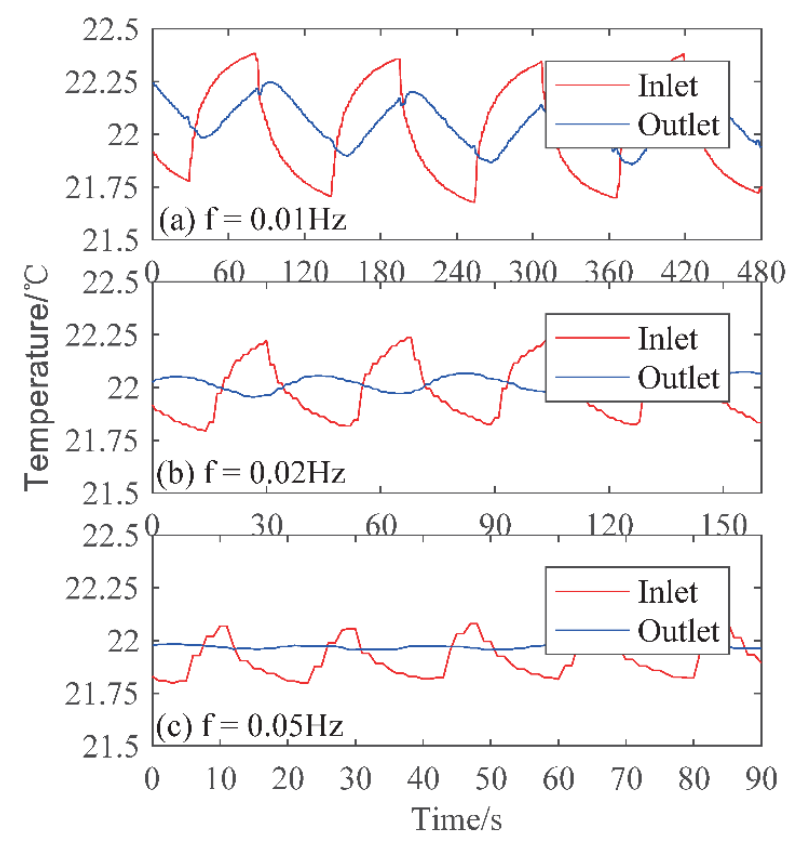

Figure 6. Temperature waveforms of CCW at inlet header and outer header of the DTFM attenuator.

Therefore, the frequency analysis of CCW temperature waveforms is carried out to illustrate the performance of fluctuation attenuation in frequency domain, as shown in Figure 7. The main frequencies of distorted CCW temperature waveforms at inlet header of the DTFM attenuator are 0.01 $\mathrm{Hz}, 0.025 \mathrm{~Hz}$, and $0.053 \mathrm{~Hz}$, respectively, while the corresponding temperature fluctuation attenuation ratios are $-3.47 \mathrm{~dB},-6.19 \mathrm{~dB}$, and $-10.97 \mathrm{~dB}$, respectively. The temperature fluctuation attenuation ratio corresponding to $0.105 \mathrm{~Hz}$ is $-15.28 \mathrm{~dB}$.

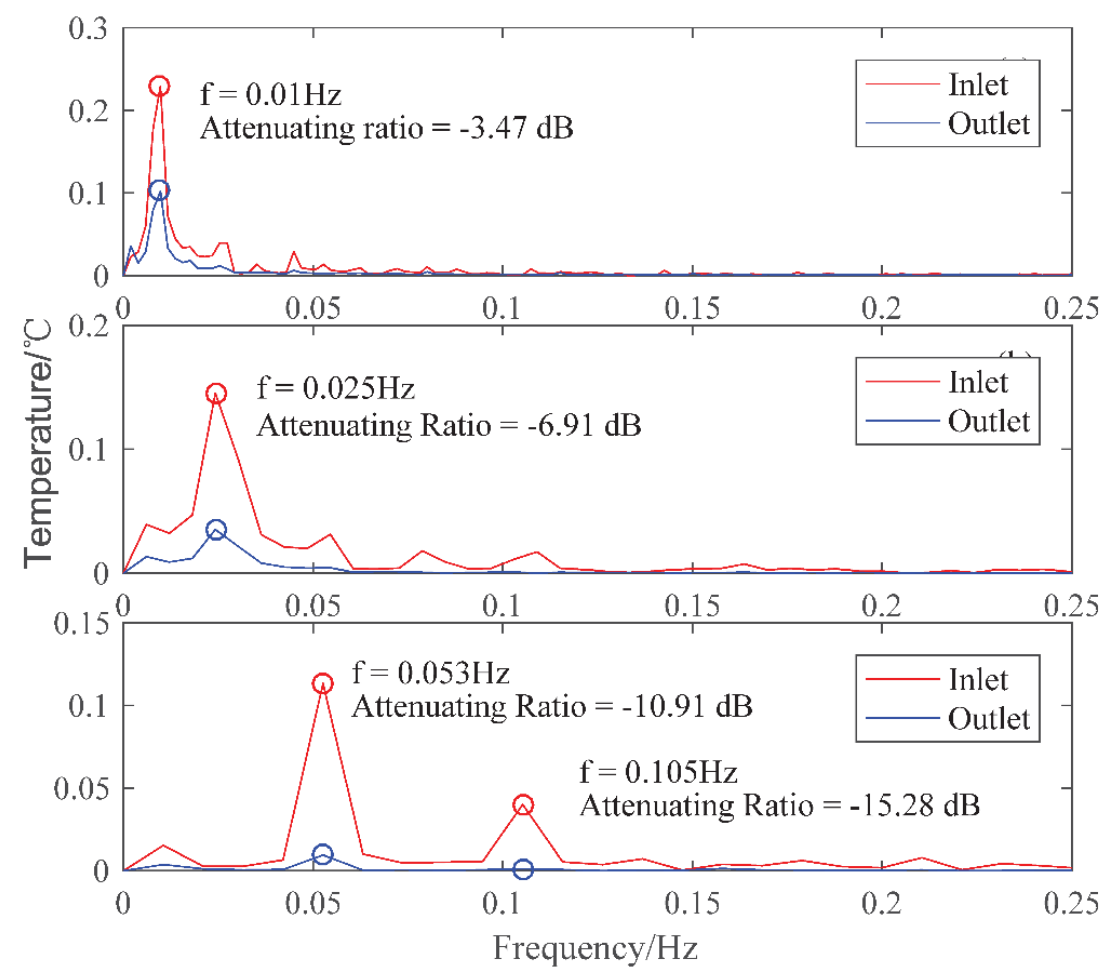

Figure 7. Performance of temperature fluctuation attenuation in frequency domain. 
The comparison of experimental results with theoretical modeling results is shown in Figure 8. It can be seen that the values of experimental results are $\sim 5 \mathrm{~dB}$ worse than the theoretical results. There are many factors which may result in the difference between experimental and theoretical values, such as indispensable approximation in the transfer functions, thermal dissipation of the experimental set up and so on. Therefore, the difference of $\sim 5 \mathrm{~dB}$ is acceptable in this work, since the trend of the experimental results agrees well with the theoretical results.

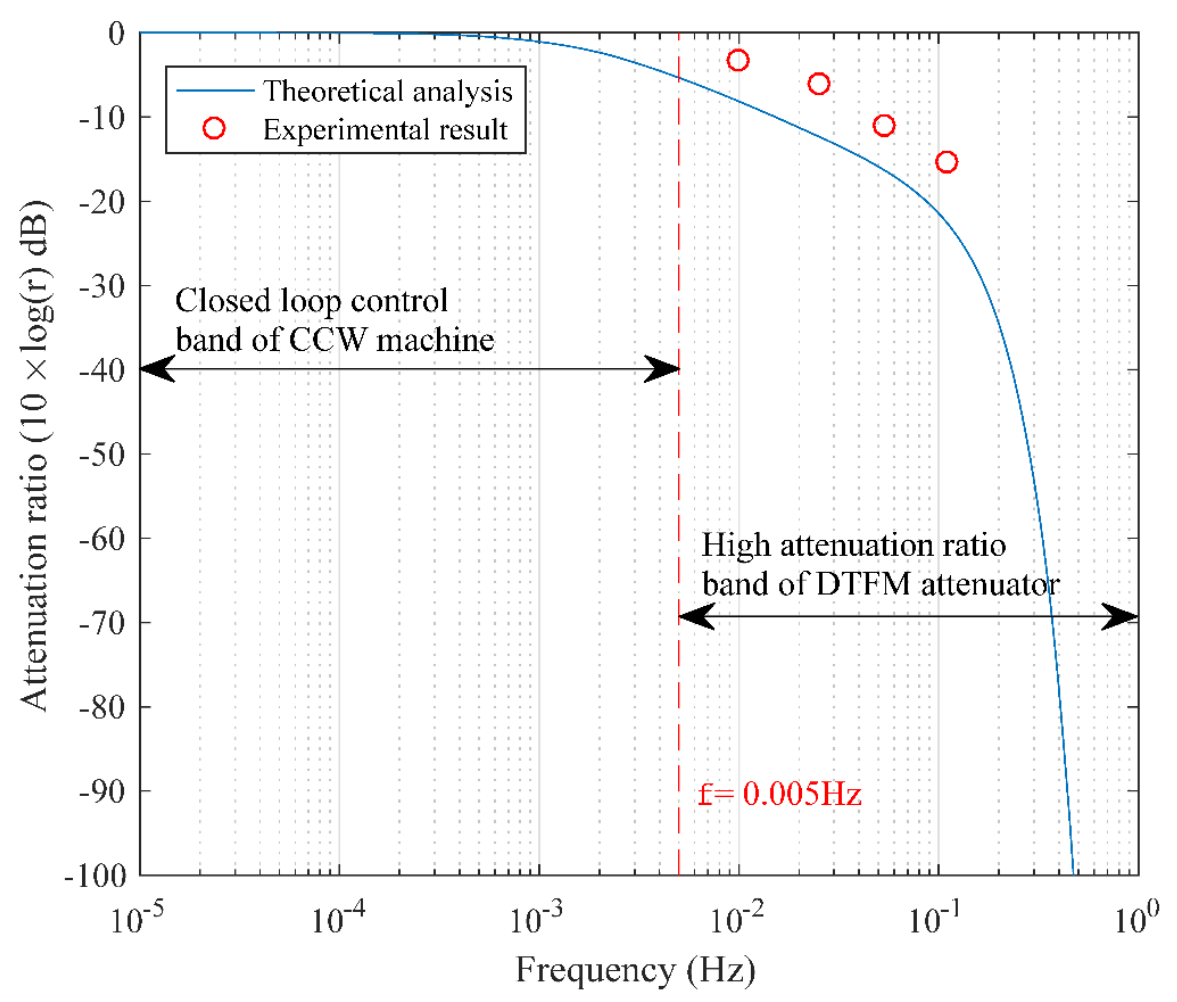

Figure 8. Experimental results of temperature fluctuation attenuation ratio (Compared with theoretical results in Figure 3).

Conventional temperature fluctuation attenuation methods can provide a super large attenuating ratio, such as more than $-60 \mathrm{~dB} @ 0.01 \mathrm{~Hz}$ presented by Lawton, K.M. [14], however, the thermal capacity medium in previous work are all non-updatable, which means that the temperature fluctuation attenuation is available around a fixed temperature. Thus, the conventional methods can not satisfy the demand of temperature fluctuation attenuation in dynamic temperature control system, since the dynamic performance of the system is sacrificed for better temperature stability by the introduced thermal inertia. Compared with conventional methods, the proposed DTFM can be applied for the applications demanding dynamic temperature control of CCW.

\section{Conclusions}

This paper proposes a dynamic thermal filtering method, which can significantly reduce the temperature fluctuation of CCW and achieve the quick response of CCW temperature control. A DTFM based attenuator is achieved with a tube-tank heat exchanger. Theoretical analysis has been carried out with the designed attenuator, and the performance of the attenuator is verified by experiments. In summary, conclusions are as follows:

1. Theoretical results indicate that the attenuator based on DTFM has low-pass characteristics for temperature fluctuation. Though there is only a few of $\mathrm{dB}$ beyond $0.005 \mathrm{~Hz}$, the temperature fluctuation can be eliminated by the closed loop feedback control of the temperature control system. 
2. The attenuation ratio of tens of $\mathrm{dB}(-3.47 \mathrm{~dB},-6.91 \mathrm{~dB},-10.97 \mathrm{~dB}$ and $-15.28 \mathrm{~dB}$, corresponding to temperature fluctuation frequencies of $0.01 \mathrm{~Hz}, 0.025 \mathrm{~Hz}, 0.053 \mathrm{~Hz}$ and $0.105 \mathrm{~Hz}$, respectively) is achieved, while the thermal capacity medium updating time is $82 \mathrm{~s}$, which means that the designed DTFM attenuator can remarkably improve the temperature stability of CCW with the response time of CCW temperature control less than one minute.

3. The conventional methods can provide quite large attenuation ratio of temperature fluctuation, but cannot satisfy the demand of temperature fluctuation attenuation from dynamic temperature control system. Compared with the conventional methods, the proposed method can be applied for the applications demanding the dynamic temperature control of $\mathrm{CCW}$, since the updatable thermal capacity medium is introduced.

4. Our further work will focus on the structure optimization of the attenuator to achieve a larger attenuation ratio with more compact size.

Author Contributions: Conceptualization, Y.L., J.C. and J.T.; Funding acquisition, J.C. and J.T.; Investigation Y.L.; Methodology, J.C. and J.T.; Project administration, J.C. and J.T.; Resources, Y.L.; Visualization, X.B. and Y.Z.; Writing-original draft, Y.L.; Writing-review \& editing, Y.L., J.C. and J.T. All authors have read and agreed to the published version of the manuscript.

Funding: This research was funded by National Natural Science Foundation of China, grant number 51675139 and the Fundamental Research Funds for the Central Universities.

Conflicts of Interest: The authors declare no conflict of interest.

\section{References}

1. Mayr, J.; Jedrzejewski, J.; Uhlmann, E.; Donmez, M.A.; Knapp, W.; Härtig, F.; Wendt, K.; Moriwaki, T.; Shore, P.; Schmitt, R.; et al. Thermal issues in machine tools. CIRP Ann. -Manuf. Technol. 2012, 61, 771-791. [CrossRef]

2. Yamada, A. Arf immersion lithography for 45-nm and beyond. Proc. Spie-Int. Soc. Opt. Eng. 2007, 6607, 66071-66081.

3. Zhao, Y.; Trumper, D.L.; Heilmann, R.K.; Schattenburg, M.L. Optimization and temperature mapping of an ultra-high thermal stability environmental enclosure. Precis. Eng. 2010, 34, 164-170. [CrossRef]

4. Cui, L.Y.; Zhang, D.W.; Gao, W.G.; Qi, X.Y.; Shen, Y. Thermal errors simulation and modeling of motorized spindle. Adv. Mater. Res. 2011, 154-155, 1305-1309. [CrossRef]

5. Tay, A.; Chua, H.T.; Wang, Y.H.; Ngo, Y.S. Equipment design and control of advanced thermal-processing module in lithography. IEEE Trans. Ind. Electron. 2010, 57, 1112-1119. [CrossRef]

6. Liu, T.; Gao, W.; Tian, Y.; Zhang, H.; Chang, W.; Mao, K.; Zhang, D. A differentiated multi-loops bath recirculation system for precision machine tools. Appl. Therm. Eng. 2015, 76, 54-63. [CrossRef]

7. Mayr, J.; Ess, M.; Pavliček, F.; Weikert, S.; Spescha, D.; Knapp, W. Simulation and measurement of environmental influences on machines in frequency domain. CIRP Ann. -Manuf. Technol. 2015, 64, 479-482. [CrossRef]

8. Li, Y.; Zhao, W.; Lan, S.; Ni, J.; Wu, W.; Lu, B. A review on spindle thermal error compensation in machine tools. Int. J. Mach. Tools Manuf. 2015, 95, 20-38. [CrossRef]

9. Manske, E.; Jäger, G.; Hausotte, T.; Füßl, R. Recent developments and challenges of nanopositioning and nanomeasuring technology. Meas. Sci. Technol. 2012, 23, 074001. [CrossRef]

10. Unni, P.K.M.; Gunasekaran, M.K.; Kumar, A. $\pm 30 \mu \mathrm{k}$ temperature controller from 25 to $103^{\circ} \mathrm{C}$ : Study and analysis. Rev. Sci. Instrum. 2003, 74, 231. [CrossRef]

11. Nagata, K.; Okumura, M.; Maio, K.; Fujii, A.; Andoh, H.; Morimura, T.; Hayakawa, H. High-resolution and high-stability electromagnetic-deflection control system for eb lithography system. Emerg. Lithogr. Technol. V 2001, 4343, 692-703.

12. Lawton, K.M.; Patterson, S.R. A high-stability air temperature control system. Precis. Eng. 2000, 24, 174-182. [CrossRef]

13. Hirasawa, S.; Koike, K.; Kawanami, T.; Shirai, K. Effect of error in predictive model of model prediction control to minimize temperature change of plate with varying heat generation. J. Mach. Manuf. Autom. 2013, 2, 71-78. 
14. Lawton, K.M.; Patterson, S.R.; Keanini, R.G. Precision temperature control of high-throughput fluid flows: Theoretical and experimental analysis. J. Heat. Transf. 2001, 123, 796-802. [CrossRef]

15. Lawton, K.M.; Patterson, S.R.; Keanini, R.G. Direct contact packed bed thermal gradient attenuators: Theoretical analysis and experimental observations. Rev. Sci. Instrum. 2003, 74, 2886-2893. [CrossRef]

16. Vít, T.; Charvat, P.; Stetina, J.; Pech, O.; Klimes, L.; Ostry, M.; Dančová, P.; Novotný, P. Experimental investigation of stabilization of flowing water temperature with a water-pcm heat exchanger. EPJ Web Conf. 2014, 67, 02046.

17. Charvat, P.; Klimes, L.; Stetina, J.; Ostry, M. Thermal storage as a way to attenuate fluid-temperature fluctuations: Sensible-heat versus latent-heat storage materials. Mater. Tehnol. 2014, 48, 423-427.

18. Alawadhi, E.M. Temperature regulator unit for fluid flow in a channel using phase change material. Appl. Therm. Eng. 2005, 25, 435-449. [CrossRef]

19. Oró, E.; de Gracia, A.; Castell, A.; Farid, M.M.; Cabeza, L.F. Review on phase change materials (PCMS) for cold thermal energy storage applications. Appl. Energy 2012, 99, 513-533. [CrossRef]

20. Klimes, L.; Pavel, C. Heuristic optimization of fluid temperature attenuator design with phase change material. In Proceedings of the International Conference on Soft Computing MENDEL, Brno, Czech Republic, 10-12 July 2012; pp. 338-343.

21. Mohebbi, R.; Rashidi, M.M. Numerical simulation of natural convection heat transfer of a nanofluid in an 1-shaped enclosure with a heating obstacle. J. Taiwan Inst. Chem. Eng. 2017, 72, 70-84. [CrossRef]

22. Sarafraz, M.M.; Safaei, M.R. Diurnal thermal evaluation of an evacuated tube solar collector (etsc) charged with graphene nanoplatelets-methanol nano-suspension. Renew. Energy 2019, 142, 364-372. [CrossRef]

(C) 2020 by the authors. Licensee MDPI, Basel, Switzerland. This article is an open access article distributed under the terms and conditions of the Creative Commons Attribution (CC BY) license (http://creativecommons.org/licenses/by/4.0/). 